\title{
GAYA KEPEMIMPINAN KEPALA SD ISLAM SWASTA DALAM MENINGKATKAN MUTU SEKOLAH DI KECAMATAN WONOSARI KABUPATEN GUNUNGKIDUL DIY
}

\author{
Lely Inayati \\ Program Pasca Sarjana \\ Universitas Muhammadiyah Yogyakarta \\ E-mail: zahralala81@yahoo.co.id
}

\begin{abstract}
Abstrak
Penelitian ini bertujuan untuk mendeskripsikan dan menganalisis tentang gaya kepemimpinan kepala sekolah dalam upaya meningkatkan kinerja guru dan tenaga kependidikan Di SD Muh Al Mujahidin dan SD IT Tunas Mulia Wonosari Gunungkidul dan menelusuri tentang faktor yang mempengaruhi gaya kepemimpinan kepala sekolah di SD Muh Al Mujahidin dan SD IT Tunas Mulia Wonosari Gunungkidul. Penelitian ini menggunakan pendekatan kualitatif deskriptif dengan rancangan penelitian studi kasus. Teknik dalam keabsahan data menggunakan kredibiltas, transferbilitas, dependabilitas dan konfirmabilitas. Hasil penelitian yaitu: (1) gaya kepemimpinan kepala sekolah disimpulkan dari 8 (delapan) aspek yang telah ditentukan oleh peneliti, 2) Dalam upaya meningkatkan mutu sekolah 2 kepala sekolah ini menggunakan 8 standar nasional pendidikan yaitu dengan melakukan peningkatan mutu pada inovasi pembelajaran, pemberdayaan guru dan tenaga kependidikan, pemberian motivasi dan pemberian penghargaan, penentuan kualifikasi kelulusan, pemenuhan sarana dan pra sarana sekolah dan perbaikan sistem pembiayaan.
\end{abstract}

Kata kunci: gaya kepemimpinan, kepala sekolah, mutu sekolah

\begin{abstract}
This research aims to describe and analyze the leadership style of principals in an effort to improve the performance of teachers and education personnel In SD Muh Al Mujahidin and SD IT Tunas Mulia Wonosari Gunungkidul and trace about the factors that influence the leadership style of principals Muh Al Mujahidin and SD IT Tunas MuliaWonosariGunungkidul. This research uses descriptive qualitative approach with case study research design. Techniques in data validity use credibility, transferbility, dependability and confirmability. The results of the research can be explained as follows for the head of SD Muh Al Mujahidin: (1) the principal leadership style is inferred from eight aspects that have been determined by the researcher, 2)So that can be understood in an effort to improve the quality of the school 2 principals using 8 national standards of education by making innovative learning, empowerment of teachers and educational staff, motivation and awarding, determination of qualification graduation, fulfillment of facilities and pre-school facilities and improvement of financing system.
\end{abstract}

Keywords: leadership style, headmaster, school quality

\section{Info Artikel}

Diterima Februari 2019, disetujui Maret 2019, diterbitkan Juni 2019 


\section{PENDAHULUAN}

Penyelenggaraan pendidikan dalam sebuah organisasi menunjukkan bahwa keberadaan organisasi pendidikan ditujukan untuk mencapai tujuan pendidikan secara lebih efektif dan efisien. Komitmen bangsa Indonesia akan pendidikan sangat jelas tercermin dalam UUD 45, khususnya pasal 31, yang menegaskan bahwa "setiap warga Negara berhak mendapatkan pendidikan". Landasan konstitusional merupakan komitmen pendidikan yang membuka peluang sebesar-besarnya bagi bangsa Indonesia berbuat yang terbaik bagi system pendidikan nasional melalui berbagai pemerataan dan pembangunan, termasuk kebijakan otonomi daerah.

Sekolah merupakan salah satu lembaga pendidikan yang dipercaya masyarakat dan Negara untuk menyiapkan sumber daya manusia yang dibutuhkan dalam pembangunan bangsa. Sebuah sekolah adalah organisasi yang komplek dan unik, sehingga memerlukan tingkat koordinasi yang tinggi. Untuk itu sangat dibutuhkan seseorang yang dapat membawa ruh perubahan terhadap dinamisasi system yang ada di sekolah.

Kepala Sekolah merupakan pemimpin pendidikan yang harus memiliki dasar kepemimpinan yang kuat. Kepala sekolah harus memiliki visi dan misi serta strategi manajemen pendidikan yang utuh dan berorientasi pada peningkatan mutu. Untuk itu kepala sekolah harus memahami kunci sukses kepemimpinannya.

Ada banyak teori kepemimpinan yang dapat digunakan dalam memimpin lembaga pendidikan khususnya sekolah. Teori teori ini dapat digunakan oleh kepala sekolah menjadi salah satu style/gaya kepemimpinan yang akan di terapkan di lingkungan sekolah walaupun ada beberapa teori yang menyatakan bahwa kepemimpinan hanya menjadi milik orang orang yang besar yang cenderung mengacu pada hal hal khusus yang tidak dimiliki orang biasa. Hanya orang orang yang memiliki ciri dan sifat tertentu yang dapt menjadi seorang pemimpin, teori ini yang sering disebut teori sifat atau teori kompetensi.

Peningkatan mutu yang merupakan sebuah filosofis dan metodologis menurut Edward Sallis adalah usaha yang membantu institusi untuk merencanakan perubahan dan mengatur agenda dalam menghadapi tekanan tekanan eksternal yang berlebihan. Sedangkan Sudarwan Danim menyetakan bahwa mutu mengandung makna derajat keunggulan suatu produk atau hasil kerja, baik berupa barang dan jasa. Upaya 
peningkatan mutu sekolah difokuskan dalam bidang pendidikan. Inti dari proses pendidikan adalah pembelajaran peserta didik. Proses pembelajaran ini mencakup sejumlah unsur utama yang mendasar yang membentuk mutu pembelajaran. Unsur unsur tersebut adalah tujuan pembelajaran, isi kurikulum, guru, sarana prasarana, dana, manajemen dan evaluasi.

Hal ini yang membuat penulis ingin mengkaji lebih dalam tentang gaya kepemimpinan kepala sekolah yang dapat meningkatkan mutu sekolah khususnya pada sekolah sekolah yang berbasis Islam. Dimana sekolah sekolah yang akan diteliti adalah sekolah yang memiliki latar belakang culture yang berbeda satu dengan yang lainnya. . Penelitian ini akan dilaksanakan di Kabupaten Gunungkidul Daerah Istimewa Yogyakarta

Dari 552 sekolah yang ada di Kabupaten Gunungkidul, peneliti hanya akan mengambil 2 sekolah yang berbasis Islam yang dalam pandangan peneliti kepala sekolah di 2 sekolah tersebut tersebut memiliki gaya kepemimpinan yang berbeda beda namun mampu menunjukkan mutu dan keunggulan sekolah masing masing . Kedua SD tersebut merupakan SD Islam Unggulan, keunggulan yang hampir sama yang tampak adalah keunggulan dalam pembentukan akidah dan karakter siswa (akhlak), jumlah siswa yang banyak dan berasal dari berbagai kecamatan di Gunungkidul, memiliki prestasi di bidang akademik dan non akademik, serta yang sangat menarik perhatian wali murid bahwa di 2 sekolah ini memiliki target kegiatan keagamaan yang tinggi.

Kajian pustaka terdahulu Rosmala Dewi yang berjudul Kinerja Kepala Sekolah : Pengaruh Kepemimpinan Transformasional, Konflik dan Efikasi Diri . Penelitian ini dilakukan di Medan dengan menggunakan populasi sejumlah 380 Kepala Sekolah Dasar sebagai Subjek Penelitian. Variabel yang diukur adalah perilaku tugas, perilaku moral dan perilaku menentang yang mana pada hasilnya disimpulkan bahwa kepemimpinan transformasional berpengaruh positif terhadap efikasi diri kepala sekolah. Peningkatan efikasi diri dapat dilakukan melalui memperbaiki kualitas kepemimpinan transformasional.

Kajian lain yang juga membahas tentang gaya kepemimpinan dilakukan oleh I Made Narsa dengan Judul Karakteristik Kepemimpinan : Transformasional versus Transaksional.Kajian ini bertujuan menelaah secara deskriptif mengenai manajemen vs. kepemimpinan, dan atau manajer vs. leader, dilihat dari sudut karakteristik utama pada 
keduanya. Hasil telaah menunjukkan bahwa ada karakteristik yang tegas yang membedakan antara manajemen dan kepemimpinan, dan antara manajer dan leader. Penelitian berikutnya juga dilakukan oleh Dewi Puspita Sari dengan judul Kontribusi Gaya Kepemimpinan Kepala Sekolah Dan Motivasi Berprestasi Guru Terhadap Mutu Pendidikan Di Gugus Rama 2 UPT Disdikpora Kecamatan Kembang Kabupaten Jepara, dalam penelitiannya Dewi meneliti kontribusi gaya kepemimpinan kepala sekolah terhadap mutu pendidikan. Populasi yang diteliti adalah semua guru sejumlah 43 orang di Gugus Rama 2 UPT Dinas Pendidikan Pemuda dan Olahraga kecamatan Kembang, Kabupaten Jepara. Metode yang digunakan dalam penelitian ini adalah Deskriptif Kualitatif melalui angket/kuisioner. Berdasarkan deskripsi data, analisis hipotesis dan pembahasan disimpulkanbahwa ada kontribusi gaya kepemimpinan kepala sekolah terhadap mutu pendidikan.

\section{LANDASAN TEORI}

Gayakepemimpinan artinya sekumpulan ciri yang digunakan pemimpin untuk memengaruhi bawahan agar sasaran oranisasi tercapai atau dapat pula dikatakan bahwa gaya kepemimpinan adalah pola perilaku atau strategi yang disukai atau sering diterapkan oleh seorang pemimpin.Gaya kepemimpinan juga didefinisikan oleh berbagai ilmuwan dengan berbedaperspektif yaitu: perspektif kompetensi/sifat,perspektif perilaku, perspektif kontingensi,transformasional dan lainlain. Northouse dan Rowe memandang kepemimpinan sebagai suatuproses dimana seseorang mempengaruhi sekelompokindividu untuk mencapai tujuan dan kesuksesan bersamaorganisasi.

Kepemimpinan didefinisikan oleh Webster sebagai pedoman, pelaksanaan, kemajuan atau keberadaanterutama di antara sekelompok orang. Ini adalah prosesmengembangkan gagasan dan visi, hidup dengan nilai yang mendukunggagasan dan visi tersebut, mempengaruhi orang atau kelompokmerangkul perilaku mereka sendiri, dan membuat keputusan tentangmanusia dan sumber daya lainnya untuk mencapai tujuan organisasi. Siagian dalam buku(education management) kepemimpinan adalah suatu kegiatan untuk mempengaruhi perilaku orang orang agar bekerjasama menuju kepada suatu tujuan tertentu yang mereka inginkan bersama. 
Umar Suharsaputra dalam bukunya yang berjudul Kepemimpinan Inovasi Pendidikan menuliskan tentang teori teori dan gaya kepemimpinan, menurut Mc Shane dan Von Gilnow terdapat 5 perspektif (teori) tentang kepemimpinan yaitu: Teori Sifat/Kompetensi; Teori sifat ini memandang bahwa sifat sifat memainkan peranan penting dalam membedakan antara pemimpin dengan bukan pemimpin, seorang pemimpin adalah mereka yang mempunyai sifat sifat tertentu yang khas. Schemerhorn mengemukakan sepuluh sifat yang mempunyai implikasi bagi kepemimpinan yang sukses yaitu : Energik, toleran terhadap stress, motivasi kekuasaan yang pro sosial, berorientasi pada prestasi, Matang secara emosi Percaya diri Integritas Melindungi (ulet,tekun) memiliki kemampuan kognitif, cerdas akademis dan sosial memiliki pengetahuan yang relevan, fleksibel.

Teori sifat pada dasasrnya adalah teori yang menitikberatkan pada karakteristik yang melekat pada diri seorang pemimpin. Teori Perilaku ; Teori Perilaku in berpandangan bahwa kepemimpinan merupakan hal utama bagi kinerja, dalam hubungan ini kepemimpinan di lihat dari perilakunya dalam menjalankan perannya sebagai pemimpin. Dalam teori perilaku ini peneliti Lowa memanipulasi ada 3 gaya kepemimpinan yaitu: 1) Authoritarian Leadership ; kepemimpinan yang bersifat direktif dan tidak ada partisipasi. Pemimpin mengambil penuh otoritas dan memikul penuh tanggungjawab organisasi 2) Democratic Leadership; pemimpin dengan gaya ini mendorong pada partisipasi bawahan untuk berdiskusi dengan menguatkan kemampuan bawahan menyampaikan pendapat 3) Laissez faire Leadership ; pemimpin memberikan kebebasan penuh pada bawahan untuk membuat keputusan sendiri, sehingga pemimpin tidak menyediakan kepemimpinan. Teori Kontingensi /situasi ; Teori ini berpandangan bahwa kepemimpinan tidak bisa hanya dijelaskan oleh satu faktor saja baik itu sifat ataupun perilaku, namun seluruh faktor situasi dimana seorang pemimpin berperan juga harus dipertimbangkan. Terdapat beberapa teori terkait kontingensi ini diantaranya: 1) Teori Kepemimpinan Kontingensi /situasional Dai Fiedler 2) Teori ini dikemukakan oleh Fred Fiedler dan rekannya, yang mana dalam teori ini secara esensial kepemimpinan merupakan hubungan kerja yang melibatkan kekuasaan dan pengaruh. Faktor faktor yang emengaruhi kepemimpinan efektif adalah : 1) Leader member relation ; menunjukkan hubungan antara pemimpin dengan kelompoknya, tingkat kepercayaan dan hormat kepada pemimpin 2) Task Structure; menunjukkan 
sifat/struktur pekerjaan/tugas bawahan apakah bersifat rutin atau kompleks. 3) Position Power; menunjukkan sejauh mana pemimpin memiliki kemampuan memengaruhi perilaku bawahan melalui kekuasaan legitimasi, kekuasaan reward dan kekuasaan memaksa. Semakin baik posisi kekuatan pemimpin semakin baik situasi kepemimpinan.

Selanjutnya Kepemimpinan Transformasional ;Konsep kepemimpinan transformasional diperkenalkan oleh Bass dan Burns. Bass dan Riggio menuliskan ada empat komponen pokok dalam kepemimpinan transformasional yaitu:Idealized Influence ; merupakan perilaku pemimpin yang menghasilkan rasa hormat (respect) dan rasa percaya diri (trust) dari orang orang yang dipimpinnya. Inspirational Motivation ; pada dimensi ini pemimpin transformasional mampu memberikan motivasi dan memberikan inspirasi para pengikutnya melalui tantangan dan pemberian makna dalam pekerjaan mereka. Intellectual Stimulation ; pada dimensi ini pemimpin transformasional memberikan dorongan kepada pengikutnya untuk lebih inovatif dan kreatif. Individulized Consideration ; pada dimensi ini pemimpin transformasional mampu memberi perhatian yang besar kepada masing masing pengikutnya.

\section{METODE PENELITIAN}

Peneliti menggunakan metode penelitian kualitatif dengan jenis penelitian studi kasus deskriptif (descriptive case study) yang mencakup studi kasus dan eksplanatoris studi kasus deskritif umumnya digunakan untuk menjawab masalah penelitian yang menyangkut pertanyaan what, how, dan why". Sumber data tersebut diperoleh peneliti secara langsung dari informan yang mengetahui secara langsung mengenai kegiatan kepala sekolah kemudian dikembangkan menggunakan teknik purposive sampling. Subjek dan Objek Penelitian Kepala Sekolah selaku pemangku kekuasaan di sekolah dan guru guru.Teknik pengumpulan data yang dilakukan dalam penelitian ini yaitu:Observasi, Wawancara, Dokumentasi Penelitian ini akan mengambil tempat di SD Muhammadiyah Al Mujahidin dan SDIT Tunas Mulia di Kecamatan Wonosari Kabupaten Gunungkidul. Analisis data digunakan untuk mengolah data yang telah terkumpul dalam suatu penelitian yang bertujuan memperoleh hasil sesuai dengan tujuan penelitian. Hasilanalisis data selanjutnya di cekkeabsahannyamelaluiderajatkepercayaan, keteralihan, ketergantungan, dankonfirmabilitas. Kepercayaanmenggunakantriangulasi, pengecekananggota (member 
check), perpanjanganwaktu pengamatan, meningkatkanketekunan, sertamelaluikecukupanbahanreferensi

\section{Upaya Peningkatan Mutu Sekolah}

Dalam upaya peningkatan mutu yang telah dilakukan SD Muhammdiyah Al Mujahidin dan SD IT Tunas Mulia adalah sebagai berikutSD Muhammmadiyah menggunakan 8 standar yang telah ditetapkan oleh BSNP dengan penambahan standar keagamaan yang ditetapkan Persyarikatan Muhammadiyah pada kurikulum ISMUBA (Al Islam Kemuhammadiyahan dan Bahasa Arab) sedangkan SD IT Tunas Mulia menggunakan Standar Mutlak dari Jaringan Sekolah Islam Terpadu dengan Kurikulum SIT yang telah dibukukan dalam standar khusus SIT. Upaya peningkatan mutu yang telah dilakukan SD Muhamdiyah Al Mujahidin adalah : Pada standar kompetensi lulusan SD Muhammadiyah Al Mujahidin telah menjadikan hapalan 1 juz sebagai syarat kelulusan, pada rata rata nilai UN 3 tahun terakhir $(24,87)$ rangking 1 tingkat kecamatan.

SD IT Tunas Mulia masih menjadikan hapalan sebagai target kelulusan walaupun pada target tersebut telah mencapai 3 juz, tingkat kecamatan sedangkan SD IT Tunas Mulia rangking 23 pada tahun 2017 dengan rerata nilai UN 3 tahun terakhir $(23,45)$. Pada pengelolaan siswa, upaya mutu di SD IT pada peningkatan pola asuh anak di rumah maupun disekolah dengan frekuensi program parenting dan mentoring tatap muka siswa yaitu satu bulan sekali untuk parenting dan satu minggu sekali untuk mentoring . Sedangkan di SD Muhammadiyah Al Mujahidin parenting dilakukan 6 kali dalam setahun berupa koordinasi guru dengan wali murid, dan mentoring siswa melalui instrumen buku Pantauan Ibadah dan buku PHBSIM (perilaku hidup bersih sehat islami dan mandiri) yang di kumpulkan dan dinilai setiap hari Senin. Pada standar Sarana dan Prasarana SD Muhammadiyah Al Mujahidin telah memiliki lahan lebih luas seluas 8 $000 \mathrm{~m} 2$, memiliki fasilitas lebih lengkap dengan adanya lab IPA, dan SD IT Tunas Mulia memiliki luas lahan $1000 \mathrm{~m} 2$, belum memiliki lab IPA, untuk fasilitas lain sudah memadai. pada pengelolaan tenaga pendidikan dan kependidikan SD Muhammadiyah Al Mujahidin memiliki ketentuan yang cukup ketat dengan adanya peraturan yang tegas dalam kode etik guru SD Muhammadiyah Al Mujahidin, sedangkan di SD IT Tunas Mulia kebijakan terhadap guru masih terlihat labil, kode etik guru belum begitu 
tersistemasi, sehingga ketegasan terhadap sebuah pelanggaran belum tampak semua masih berdasar pada kesadaran guru dan karyawan yang bekerja disana.Pada standar pembiayaan , SD Muhammadiyah Al Mujahidin mengelola semua dana yang masuk dengan swa kelola sedangkan SD IT Tunas Mulia untuk penggajian guru dan dana komite dikelola oleh yayasan Bina Ummat sehingga pengembangan sekolah menunggu keputusan yayasan. Pada standar penilaian cenderung sama

\section{Penerapan Gaya Kepemimpinan Kepala Sekolah}

Gaya kepemimpinan kepala SD Muhammadiyah Al Mujahidin Wonosari Gunungkidul menunjukkan bahwa kepala sekolah berorientasi pada delapan aspek untuk menjadi kepala sekolah yang profesional yaitu perilaku keseharian, pendelegasian tugas, pengambilan keputusan, pengawasan, pengembangan sekolah, komunikasi, motivasi dan penghargaan,

Tabel 1.

Karakteristik Gaya Kepemimpinan Temuan di Lapangan

\begin{tabular}{|c|c|c|}
\hline Aspek Karakteristik pada & Temuan di lapangan & Gaya kepemimpinan \\
\hline Perilakukeseharian & 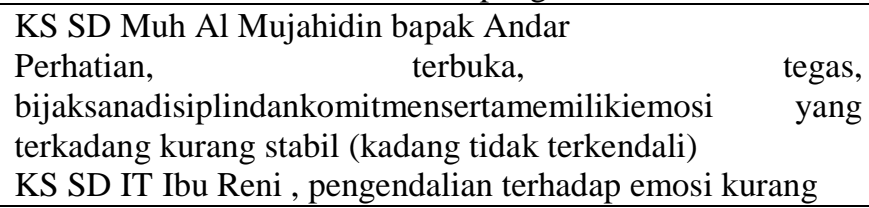 & $\begin{array}{l}\text { Kelompok/timVision } \\
\text { erDemokrasi }\end{array}$ \\
\hline Pendelegasian tugas & $\begin{array}{l}\text { Pendelegasiantugasdilakukansecaraadil, } \\
\text { meratadandisesuaikandenganbidangkeahlian, } \\
\text { memberikanpengarahanterlebihdahulu, } \\
\text { pemberiantanggungjawabdenganmelibatkandanmemberdaya } \\
\text { kanseluruhpersonil } \\
\text { Dalam hal ini Pak Andar terus memantau tugas masing } \\
\text { masing. sedangkan Bu Reni seringkali lupa untuk } \\
\text { menindaklanjuti tugas yang telah diberikan }\end{array}$ & $\begin{array}{l}\text { Situasional } \\
\text { Kontingensi }\end{array}$ \\
\hline Pengambilan keputusan & $\begin{array}{l}\text { Pak Andar dan Bu Reni sama dalam hal } \\
\text { mufakatdenganmengundangseluruhpersonilsekolah, } \\
\text { pengambilankeputusanbersamamelaluikegiatanrapatdengan } \\
\text { memberikaninformasidarilembaga yang menaungisekolah } \\
\text { (dinaspendidikan dan Majelis Pendidikan di yayasan an } \\
\text { uptd) untukkemudiandipecahkan/dicarisolusisecarabersama, } \\
\text { melakukankoordinasidenganpembagiantugas, } \\
\text { kepalasekolahselaluterlibatdalampengambilankeputusan }\end{array}$ & $\begin{array}{l}\text { Demokrasi } \\
\text { Transaksional }\end{array}$ \\
\hline Pengawasaan & $\begin{array}{l}\text { Pak Andar Guru: supervisi administrasi dan supervisi } \\
\text { pembelajaran (kunjungan kelas) dan mengadakan evaluasi } \\
\text { dan tindak lanjut kepada Tenaga kependidikan (staf): } \\
\text { melakukan kontrol/pemantaua n secara langsung dengan } \\
\text { menanyakan progress dari tugas yang telah dikerjakan. } \\
\text { Bu Reni sudah melakukan Supervisi namun belum ada } \\
\text { tindak lanjut }\end{array}$ & $\begin{array}{l}\text { Visioner } \\
\text { - }\end{array}$ \\
\hline Pengembangan sekolah & Memiliki antusiasme dalam mengembangkan sekolah, & Transformasional \\
\hline
\end{tabular}




\begin{tabular}{|l|l|l|}
\hline & $\begin{array}{l}\text { seperti mengembangkan ekstrakurikuler, mengembangkan } \\
\text { pembelajaran dengan berinovas membuat program }\end{array}$ \\
tambahan belajar bagi peserta didik kelas VI, program sudut \\
baca di tiap tiap kelas, gazebo dan taman baca, \\
mengembangkan kualitas guru dan tenaga kependidikan \\
guna meningkatkan kinerja guru dengan memberdayakan \\
guru dan tenaga kependidikan, mengikutsertakan guru dan \\
tenaga kependidikan dalam kegiatan pelatihanpelatihan, \\
workshop, pembinaan serta bekerjasama dengan lembaga \\
lembaga dan perusahaanperusahaan yang mampu \\
menciptakan, pengembangan lahan dan ruang kelas. Namun \\
dalam pengembangan sekolah SD Muh Al Mujahidin lebih \\
berkembang dengan adanya 22 kelas paralel,dan SD IT baru \\
14 kelas paralel @ 28-30 siswa
\end{tabular}

\section{KESIMPULAN}

Gaya kepemimpinan kepala sekolah di SD Muh Al Mujahidin dan SD IT Tunas Mulia Wonosari Gunungkidul dalam upaya meningkatkan mutu sekolah menunjukkan ciri-ciri sebagai berikut.

a. Kepala sekolah SD Muh Al Mujahidin dalam perilaku keseharian menunjukkan perhatian salah satunya dengan memberikan dispensasi pada ibu menyusui untuk pulang lebih awal, terbuka dan tidak menutupi mengenai aktivitas kepala sekolah, tegas dalam bertindak, disiplin dengan mematuhi kebijakan yang telah dibuat dan komitmen untuk tidak melanggar dan menerima konsekuensi apabila melakukan pelanggaran, namun untuk emosi belum bisa stabil. Sedangkan Kepala SD IT Tunas Mulia juga memberikan perhatian dalam memberikan dispensasi penambahan waktu pada guru yang belum menyelesaikan administrasi guru dari waktu yang telah ditentukan. Untuk emosi terkadang masih butuh berlatih lebih sabar

b. Pendelegasian tugas yang diberikan oleh kepala sekolah di SD Muh Al Mujahidin dan SD IT Tunas Mulia Wonosari Gunungkidul dilakukan dengan adil dan memberikan pengarahan terlebih dahulu mengenai kejelasan tugas . 
c. Pengambilan keputusan yang dilakukan oleh kepala sekolah Di SD Muh Al Mujahidin dan SD IT Tunas Mulia Wonosari Gunungkidul dengan melibatkan seluruh personil sekolah baik guru, tenaga kependidikan, penjaga sekolah, petugas kebersihan, dan tenaga keamaan untuk mencapai keputusan bersama/mufakat.

d. Pengembangan sekolah yang dilakukan oleh kepala sekolah Di SD Muh Al Mujahidin dan SD IT Tunas Mulia Wonosari Gunungkidul mencakup beberapa aspek, meliputi pengembangan sarana dan prasarana sekolah, pengembangan pembelajaran, pengembangan ekstrakurikuler, dan pengembangan guru dan tenaga kependidikan yang dilakukan secara bertahap dan berkesinambungan.

e. Pengawasan yang dilakukan oleh Kepala SD Muh Al Mujahidin Wonosari Gunungkidul berbeda antara guru dan tenaga kependidikan. Pengawasanuntuktenagakependidikandilakukansecaralangsungdenganadanya buku pantauan progressdaritugas yang diberikan. Sedangkanuntuk guru dilakukan supervise administrasi yang dilakukansetiapawal semester dan supervise pembelajaran (kunjungankelas) yang dilakukanpadatiapbulandenganvolume 2-3 orang guru kelas. Di SD IT sudah melakuakn supervisi terhadap guru tetapi belum ada tindak lanjut

f. Komunikasi yang dilakukan oleh kepala sekolah di SD Muh Al Mujahidin dan SD IT Tunas Mulia Wonosari Gunungkidul dengan komunikasi dua arah, terbuka sehingga tidak ada yang ditutup-tutupi dari staf serta menggunakan bahasa-bahasa yang mudah dipahami oleh bawahan.

g. Motivasi yang diberikan oleh kepala sekolah di SD Muh Al Mujahidin dan SD IT Tunas Mulia Wonosari Gunungkidul berupa pemenuhan kebutuhan guru dan tenaga kependidikan, baik kebutuhan fisik seperti rasa aman dan rasa nyaman, kebutuhan fisiologi seperti makan dan minum, kebutuhan pembelajaran seperti media pembelajaran, kebutuhan harga diri seperti adanya pengakuan dari kepala sekolah mengenai kemampuan personil sekolah, dan kebutuhan aktualisasi diri seperti memberikan kesempatan untuk menunjukkan kemampuan dalam kegiatan lomba serta pemberian dorongan/dukungan agar semangat dalam bekerja.

h. Penghargaan yang diberikan oleh kepala sekolah di SD Muh Al Mujahidin berupa pengakuan yang dituangkan dalam pemberian sejumlah uang dan diumumkan di 
depan wali murid dan tamu undangan pada acara wisuda dan SD IT Tunas Mulia

Wonosari Gunungkidulbelum menerapkan hal ini .

\section{SARAN}

1. Untuk meningkatkanmutu sekolah di mulai tenaga kependidikan, sebaiknya memberlakukan sistem jurnal harian kepada staf tata usaha dan staf perpustakaan agar memudahkan dalam pemantauan/pengawasan kinerja dari tenaga kependidikan tersebut. Untuk meningkatkan kedisiplinan guru dan tenaga kependidikan, sebaiknya kepala sekolah menerapkan sistem reward dan punishment.

2. Untuk memudahkan pengelolaan sekolah dan tercapainya visi dan misi sekolah, sebaiknya disegerakan membuat rencana pengembangan sekolah (rps) dan rencana strategis (renstra). dengan menggunakan planning, organizing dan controlling

\section{DAFTAR PUSTAKA}

ChiomaEuriel Uzohue. 2016, Japheth Abdulazeez Yaya2, Oluseyi A. Akintayo AReview of Leadership Theories, Principles, Styles and their Relevance to Management ofHealth Science Libraries in Nigeria ChiomaEurielUzohueJournal of Educational Leadership and Policy Vol. 1, pp.

DewiRosmala 2012, Pengaruh Kepemimpinan Transformasional, Konflik dan Efikasi Diri dalam Jurnal Ilmu Pendidikan. Jilid 18 Nomor 2

Uhar Suharsaputra, Kepemimpinan Inovasi Pendidikan, Bandung : Revika Aditama

Kepala Sekolah Dan Motivasi Berprestasi Guru Terhadap Mutu Pendidikan Di Gugus Rama 2 Upt Disdikpora Kecamatan Kembang Kabupaten Jepara dalam Jurnal JMP, Volume 2 Nomor 1, April 2013

M. Sirozi. 2009. PolitikPendidikan. Jakarta : Raja Grafindo Persada.

Rifa'I Veithzal Kepemimpinan dan Perilaku Organisasi, Jakarta: PT Raja Grafindo Persada

RivaiVeithzal, SylvianaMurni, 2010. Education Management, Jakarta :Rajawali Pers

Tim Dosen UPI 2009, Managemen Pendidikan Bandung: Alfabeta

Ulfatin, N. 2013.MetodePenelitianKualitatif di BidangPendidikan.Malang: Bayumedia Publishing h 60. 
Vol. 3 No. 2, Bulan Juni Tahun 2019

p-ISSN : 2541-6782, e-ISSN : 2580-6467

Wahyosumidjo

2001

KepemimpinanKepalaSekolahTinjauanTeoritikdanPermasalahannya,Jakarta

Raja 